\title{
Failure of CFRP airframe sandwich panels under crash-relevant loading conditions
}

\author{
R. Sturm ${ }^{*}{ }^{1)} \cdot$ Y. Klett $^{2)} \cdot$ Ch. Kindervater ${ }^{1)} \cdot$ H. Voggenreiter ${ }^{1)}$ \\ 1) Institute of Structures and Design, German Aerospace Center (DLR), Germany \\ 2) Institute of Aircraft Design, University of Stuttgart, Germany
}

\begin{abstract}
New aircraft fuselage concepts have to prove equivalent crashworthiness standards compared to conventional metallic fuselages for certification. Brittle failure mechanisms of CFRP structures make the verification of equivalent crashworthiness for novel CFRP fuselage concepts challenging since conventional metal fuselages absorb a significant part of the kinetic energy by plasticization. In this context, the damage initiation and failure of twin-walled fuselage panels were investigated under crash relevant bending-compression loads. Since the sandwich failure is initiated by core failure, a trigger concept for CFRP composite sandwich panels was developed based on local modifications in the fold pattern of the core for controlled failure initiation. By locally adjusting the collapse strength of the core in normal direction, the failure position and failure load can be adapted according to the defined kinematic hinge requirements. The core trigger concept was validated in experiments with triggered and untriggered sandwich panels under identical loading conditions.
\end{abstract}

\section{Introduction}

Due to increasing fuel prices, the significance of the structural weight has grown steadily with each generation of aircrafts. Sandwich structures with composite facesheets are commonly recognized as a promising concept for structural airframe design of lightweight transport aircraft. Before a new airframe design can be applied to primary structures the certification authorities require proof of safety standards equivalent to the ones achieved in conventional aircraft design. Currently, the crashworthiness of a CFRP fuselage is of high interest for the aircraft industry since the fuselages of the newest long-range transport aircraft generation consist of carbon composites. Since the use of composites as the primary material in a fuselage is seen as an unconventional design feature, certification authorities released a special condition "Crashworthiness" [1] for the B787 which states that the fuselage concept has to prove crashworthiness standards equivalent to a conventional metal fuselage design. Brittle failure mechanisms of CFRP structures make the verification of equivalent crashworthiness for CFRP fuselage concepts challenging since conventional metal fuselages absorb a significant portion of the kinetic energy by plasticization. In order to maintain the required equivalent crashworthiness new strategies for energy absorption during crash have to be found.

In the field of energy absorption management for composite fuselages different strategies were identified in various research programs. The most common energy absorption strategy is the application of composite crushing. If a composite structure is designed in certain way, the structure disintegrates under compression through a complex interaction of failure modes that include delamination, matrix cracking and fibre breakage [2-3]. A stable crushing can be initiated by trigger mechanisms, such as chamfered edges or dropped plies in the laminate. As soon as the crushing mode is initiated the structure shows an excellent energy absorption capacity which offers significant performance benefits over other materials in terms of their specific energy absorption [2]. Thus energy absorbers which use the crushing mode during crash are widely used in the field of automotive and aerospace. Whilst crushing devices are currently used mainly in modern military helicopters, recently there is a high interest in using crushing to improve the crashworthiness of CFRP aircraft fuselages. 
Especially the vertical struts below the cargo crossbeam are seen as possible installation area for crushing devices, since they are mainly loaded in compression during crash. The crushing of the vertical cargo struts is a main design feature for the energy absorption management of the Boeing 787 aircraft [15].

However, all surrounding structural members of the fuselage have to be designed to withstand all occurring crash loads without failing. As high trigger forces are required to secure a robust crushing, the crash kinematics requires, especially for the frame components below the passenger floor, a stiff structural design. Due to the cylindrical shape of aircraft fuselages, frames are mainly loaded under bending loads during crash. Therefore instead of sizing frames according to the static requirements, the structural sizing depends highly on the bending loads during the crash load case. Hence, despite the fact that the crushing mode with its high specific energy absorption capability is used, the crash kinematic which is called "bend frame concept" is linked to a significant weight penalty as the surrounding structural members especially frames and cargo crossbeams have to be overdesigned with respect to their static requirements.

Current research projects addressing this topic see high lightweight potential by replacing the bend frame concept with a more natural crash kinematics concept. In this crash concept, energy absorption by crushing is replaced by progressive frame failure. In this approach frames have to absorb sufficient energy during their bending failure and, on the other hand, have to fail in a progressive predefined manner such that a robust crash kinematics is obtained. Therefore so called "kinematic hinges" have to be developed which enable a controlled frame failure with sufficient energy absorption capability in the post failure domain. While the specific energy absorption of composite structures can exceed metal under pure compression loads, the brittle failure mode under bending loads limits their energy absorption capability during the hinge development. For visualisation, the different failure behaviour for CFRP composite - and metallic frames under bending loads is shown in Figure 1.

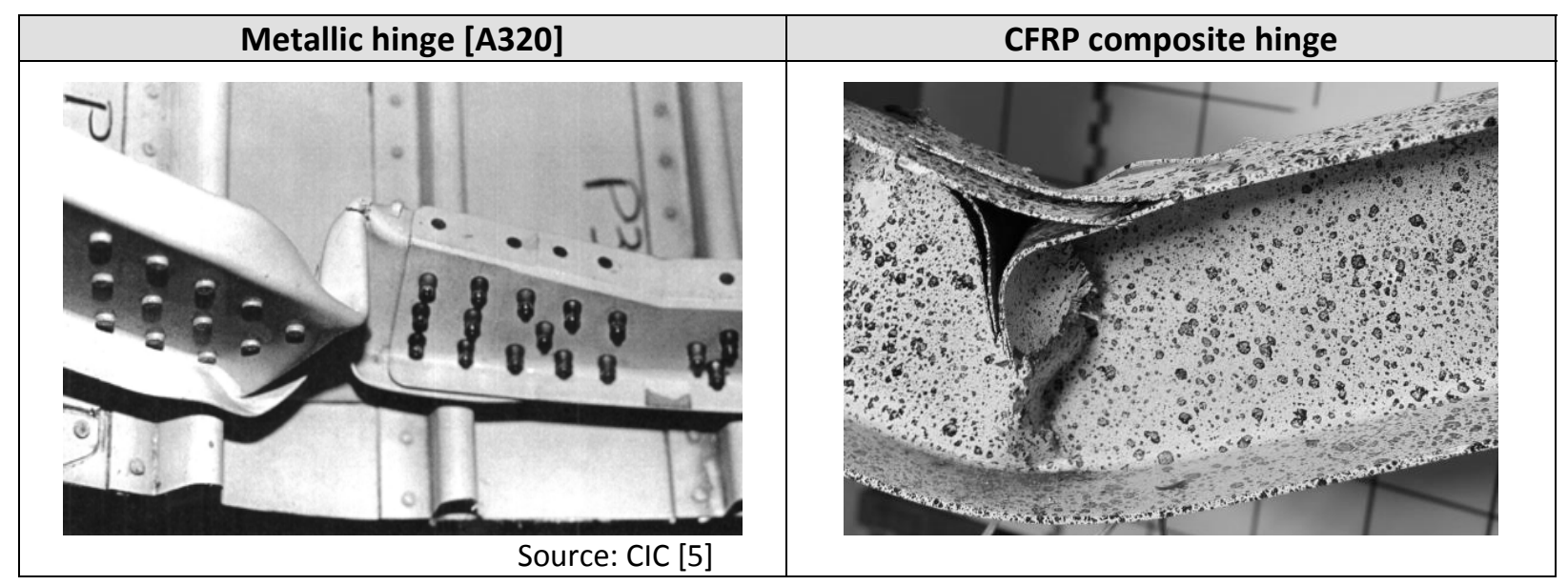

Fig. 1: Exemplary pictures of metallic and CFRP composite frame failure under crash relevant loads

The importance of kinematic hinges for CFRP fuselages was also identified by Waimer [19] who performed crash simulations on section level under pure vertical impact condition. In this investigation energy absorbing components such as failing frame regions and struts were included as macro elements and necessary absorption characteristics for the different installation area were identified by calibration of the macro characteristics. The crash studies highlighted the importance of the installation of kinematic hinges for a crashworthy CFRP fuselage concept; especially if the vertical acceleration loads of the passengers should not exceed values typical for the metallic reference design. Whilst experimental and numerical studies were already performed on CFRP frame segments $[4,6]$, there is a limited understanding of the failure mechanisms of CFRP sandwich panels under crash relevant loads. Since sandwich structures with composite facesheets are commonly recognized as a promising concept for structural airframe design of future lightweight transport aircraft, the presented study contributes to assess the crashworthiness potential of twin-walled fuselage concepts. 
Foldcore is currently considered and investigated for future fuselage applications since the open cellular design of foldcore cells would solve the problem of humidity accumulation of closed cellular sandwich cores like honeycombs [7] [9]. Foldcore is a comparably novel core concept and can be produced out of different materials. In the presented study the foldcore, which consisted out of aramid paper with randomly oriented aramid fibres embedded in phenolic resin, was produced by the University of Stuttgart. Besides the manufacturing and quality management, especially the simulation of folded core structures is challenging due to its complex damage behaviour. Therefore, a detailed understanding of the material and reliable numerical simulation strategies are required for the design and qualification process. Limited research has been published in this field. The manufacturing process of folded structures is described in detail by Klett [29]. Kärger [20] investigated experimentally folded core structures under combined transverse compression and shear forces and compared stiffness and failure behaviour to honeycomb structures. The material characterisation process and virtual determination of the material properties using implicit and explicit codes are described by Fischer [27]. Impact resistance against high velocity impact loads and a corresponding explicit simulation strategy were presented by Kilchert [17] and Sturm [24]. Low velocity impact behaviour of folded sandwich structure were investigated and simulated by Heimbs [18] and R.S. Thomson [21]. Mainly three types of modelling methodologies can be found in the literature, which can be used to model cellular core structures made out of Aramid paper. Firstly, cellular core structures can be modelled using a solid representation [28]. However, the strong nonlinearity of folded structures due to its instability failure limits its correlation quality [17]. Using a detailed shell representation of the folded core the instability failure can be simulated in more detail. Hereby Aramid paper can be modelled using an elastic-plastic material description [24]. The advantage is the reduced number of material parameters required to define the material behaviour. The detailed composition of the Aramid paper is only addressed in the multi-layered material description developed in the CELPACT project [17]. Hereby the different fibre and matrix distribution over the thickness is addressed by a multi-layered shell modelling approach in which each layer is described by a different material and damage behaviour.

\section{Investigation of CFRP sandwich panels under crash relevant loads}

For the identification of crash relevant loads, numerical crash studies were conducted on a generic twin-walled single aisle fuselage section. The design of the fuselage, the passenger floor and the cargo floor concept were based on released research studies performed by EADS IW [14] and DLR [7]. For improved energy absorption capability a sine-wave beam for crushing was positioned under the cargo crossbeam. The generic fuselage section had a length of $3 \mathrm{~m}$ and was equipped with 18 dummies. Numerical crash simulations, performed under a vertical impact velocity of $22 \mathrm{ft} / \mathrm{s}$, indicated that the critical fuselage segments between cargo-floor and vertical-strut are loaded under a combination of bending and compression loads. To simplify the notation, a short description is introduced for the ratio of bending $(\mathrm{kNmm})$ and compression loads $(\mathrm{kN})$, which describes the ratio of bending to compression loads in the structural components

\section{$A=$ bending moment / normal force $[\mathrm{mm}]$}

Figure 2 shows the ratio of bending $(\mathrm{kNmm})$ and compression loads $(\mathrm{kN})$, which was extracted form a section output at the highlighted fuselage position. The results show that in the initial crash phase (the crushing of the sine wave beam) a ratio of approximately $A=100 \mathrm{~mm}$ is obtained, which increases up to $A=200 \mathrm{~mm}$ in the second crash phase (elastic deformation of cargo crossbeam and frames). During frame failure, the development of a kinematic hinge above the vertical strut and below the passenger crossbeam, a drop in the ratio is obtained at approximately $70 \mathrm{~ms}$. The section output indicates a bending to compression ratio of approximately $A=200 \mathrm{~mm}$. Hence, if failure or triggering of the fuselage segment between cargo crossbeam and vertical strut has to be investigated, it is beneficial to identify the failure under this crash relevant loading condition. This finding is consistent with the kinematic crash studies on monolithic single aisle composite aircraft fuselages presented by Waimer [19], who also describes a bending to compression ratio of $A=200 \mathrm{~mm}$ during frame failure in the same frame segment. 


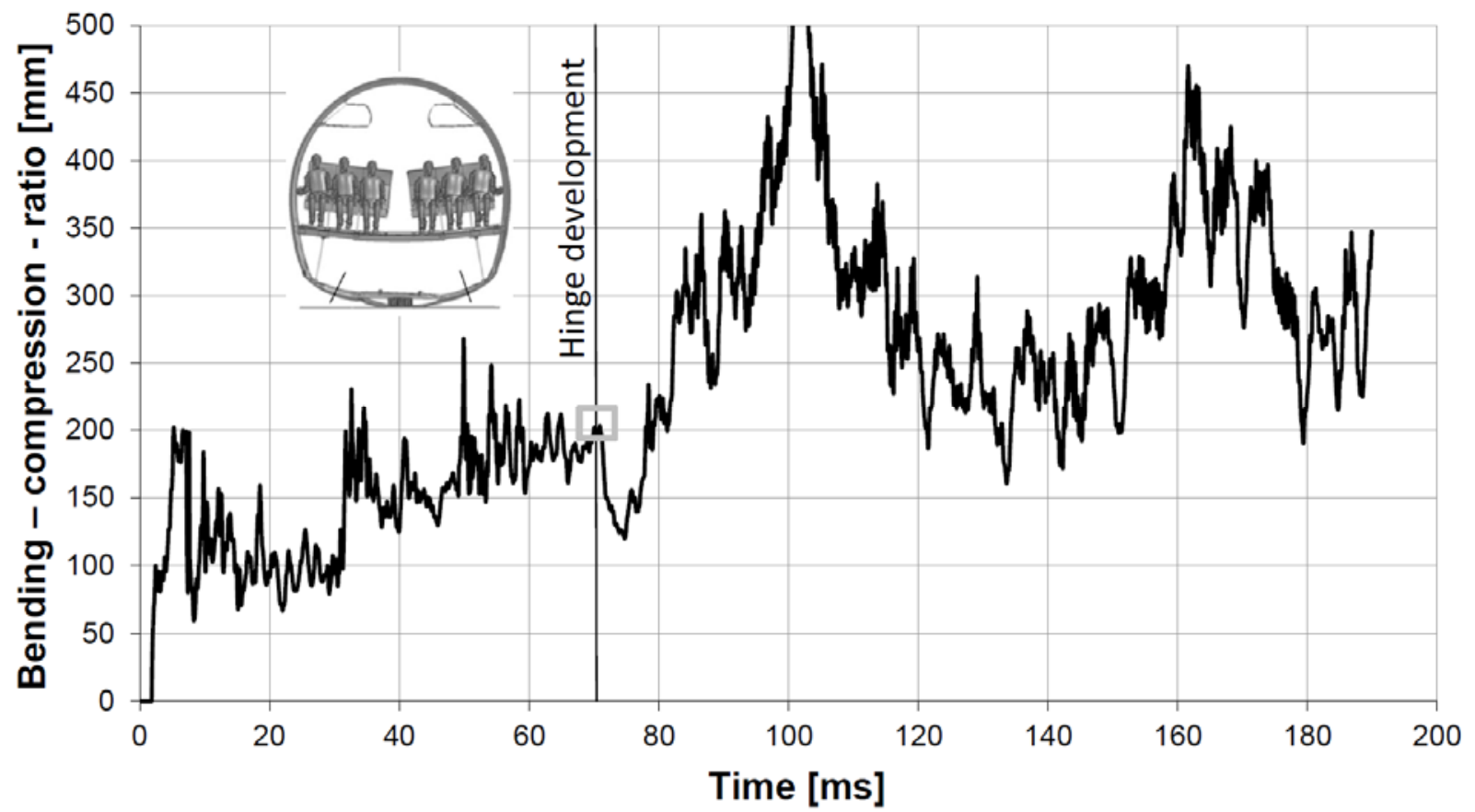

Fig. 2: Assessment of crash relevant loading condition of a twin-walled fuselage section at a favourable kinematic hinge position

Simplifying the test condition using a four-point-bending test poses the risk, that higher failure loads or in the worst case a different failure mode develops in the experiment. An experimental fixture was developed that enables the testing of fuselage segments under various combinations of bending to compression loads. The main design features of the fixtures are shown in Figure 3. In the fixture the test panel is positioned eccentric to the loading axis. With the definition of the eccentricity the loading condition of the panel can be adjusted. Stiff leverage devices fastened to the test panel insure an approximately rigid structural loading. During the test condition a cylindrically shaped stamp quasistatically loaded the test specimen until failure.
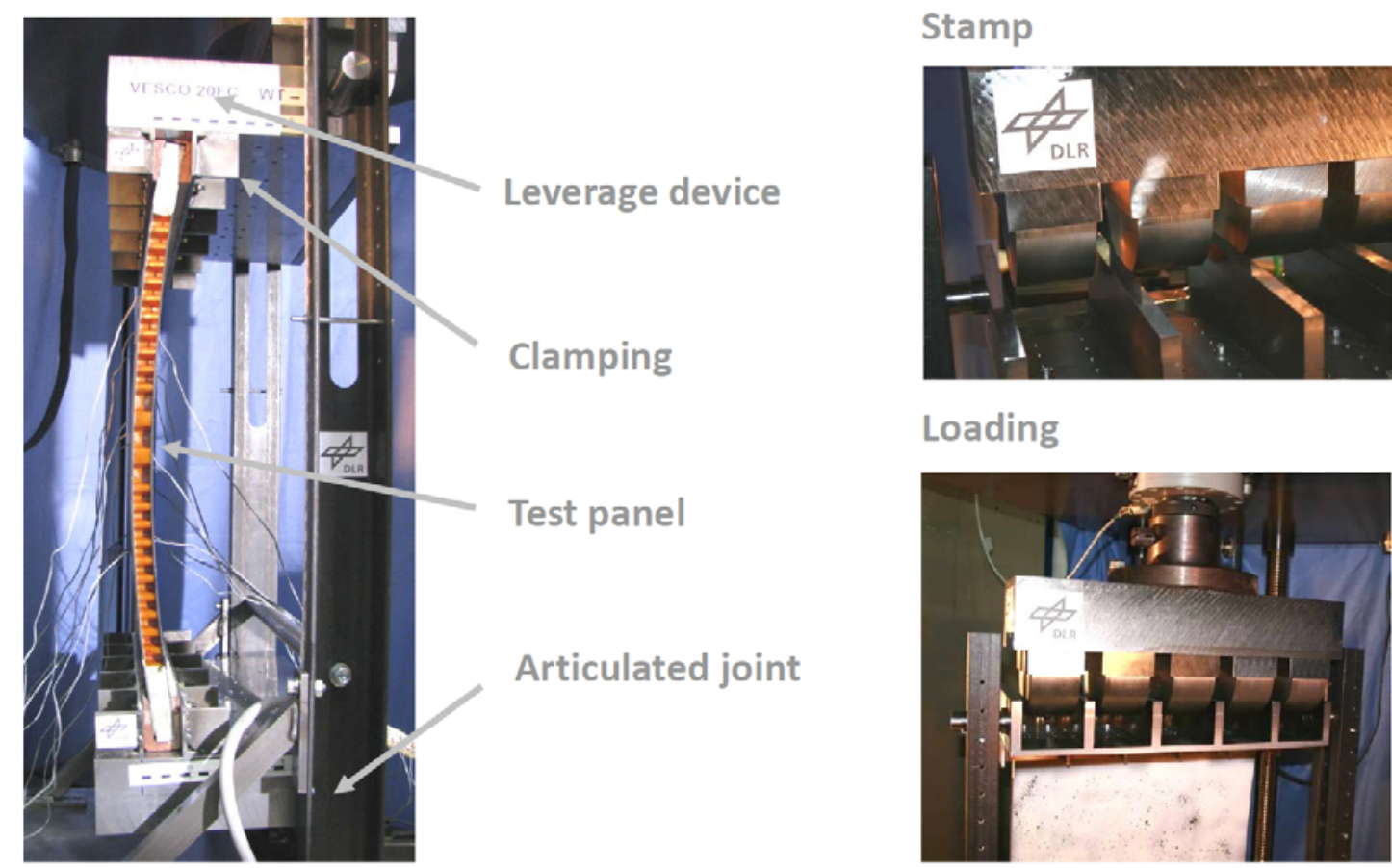

Clamping

\section{Loading}

Test panel

Articulated joint

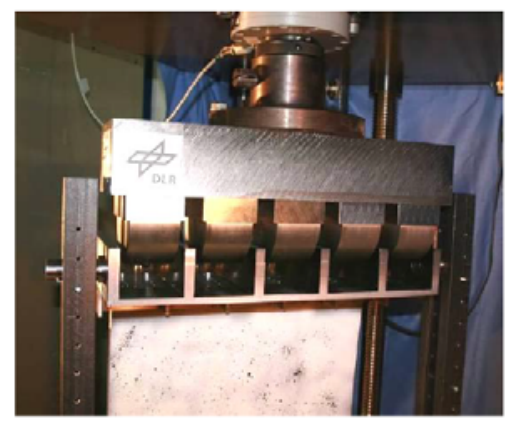

Fig. 3: Picture of the test device for combined bending - compression loading 
In the presented study, the experimental fixture was used to test fuselage relevant sandwich panels under the numerically assessed combination of bending and compression loads $[A=200 \mathrm{~mm}]$. The facesheets of the test panels consisted of two identical $2 \mathrm{~mm}$ thick Cytec HTS/977-2 prepreg laminates with a laminate setup of $\left[90^{\circ} / 0^{\circ} / 90^{\circ} / 0^{\circ} / 0^{\circ} /+45^{\circ} /-45^{\circ} / 0^{\circ}\right]_{s}$ where the $0^{\circ}$ direction is oriented in flight direction. To avoid failure initiation due to the load introduction the core material was replaced by Aluminium inlays directly at the panel-fixture interface.

The tests were performed on a Zwick Roell 1475 TM universal testing machine. During the test, the stamp was displaced constantly with a velocity of $5 \mathrm{~mm} / \mathrm{min}$ until failure. A $100 \mathrm{kN}$ load cell was used for force measurements and the displacement was obtained directly from the stamp. Up to 18 strain gauges were used per specimen to capture local strains.

Figure 4 shows the deformation and the failure under the crash relevant bending to compression ratio of $200 \mathrm{~mm}$. During the experiment the test panel deflected significantly before failure was initiated. A compression stamp load of $29.6 \mathrm{kN}$ was measured at panel failure. The deflection capability of the test panel and the failure load indicate that unstiffened sandwich panels are able to store significant elastic energy before failure. However, during the test the structure did not fail at the expected highly loaded central panel position. Instead the panel failed near the intersection of foldcore to Aluminium inlay.

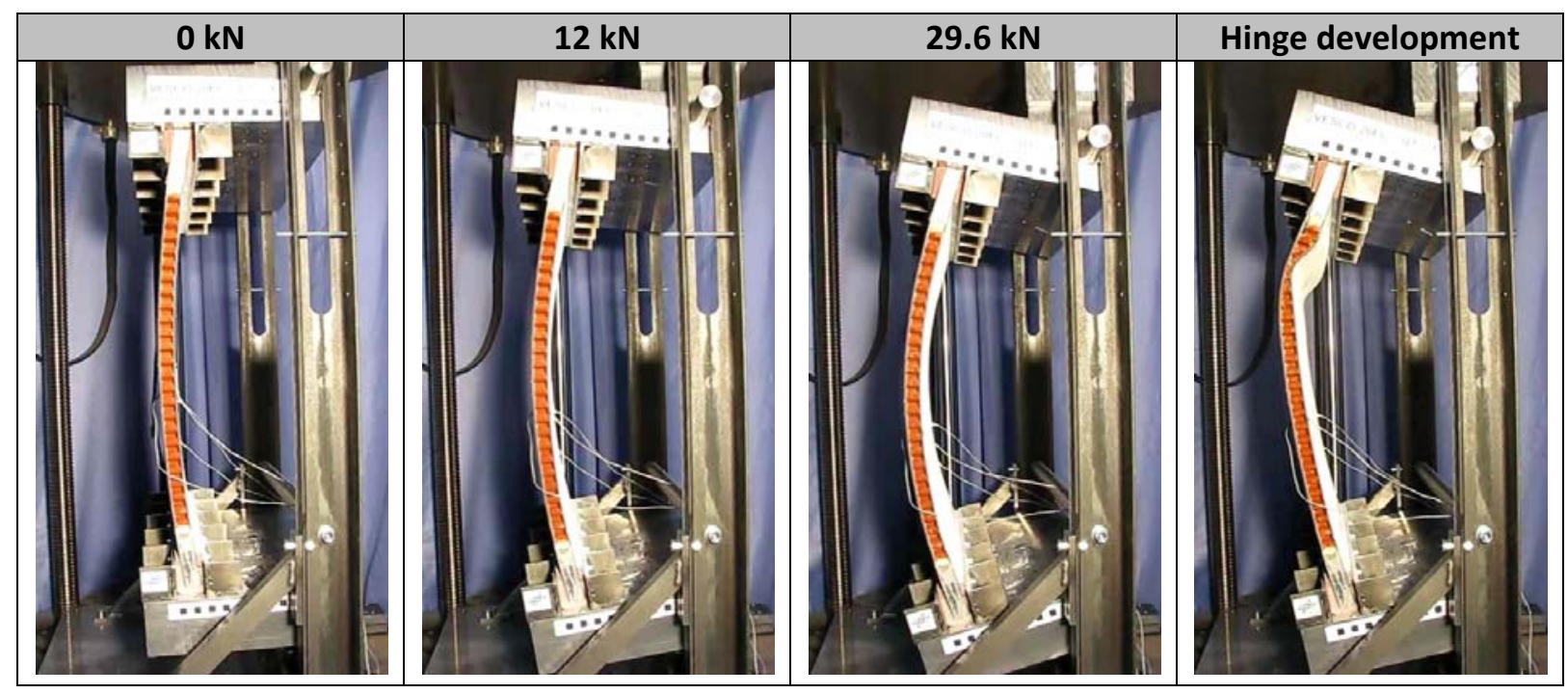

Fig. 4: Deformation and failure of a fuselage sandwich panel with foldcore under a bendingcompression ratio of $200 \mathrm{~mm}$

Despite the stiffening of the highly loaded edge regions local stress concentrations due to the changing core stiffness initiated the panel failure during the experiment. Hence, local stress concentrations exceeded the failure strength of the foldcore which led to subsequent failure of the test panel. During failure the elastic stored energy in the panel is absorbed mainly due to crushing of foldcore material at the failure region. Interestingly the facesheets of the panel were not affected severely by the failure. 

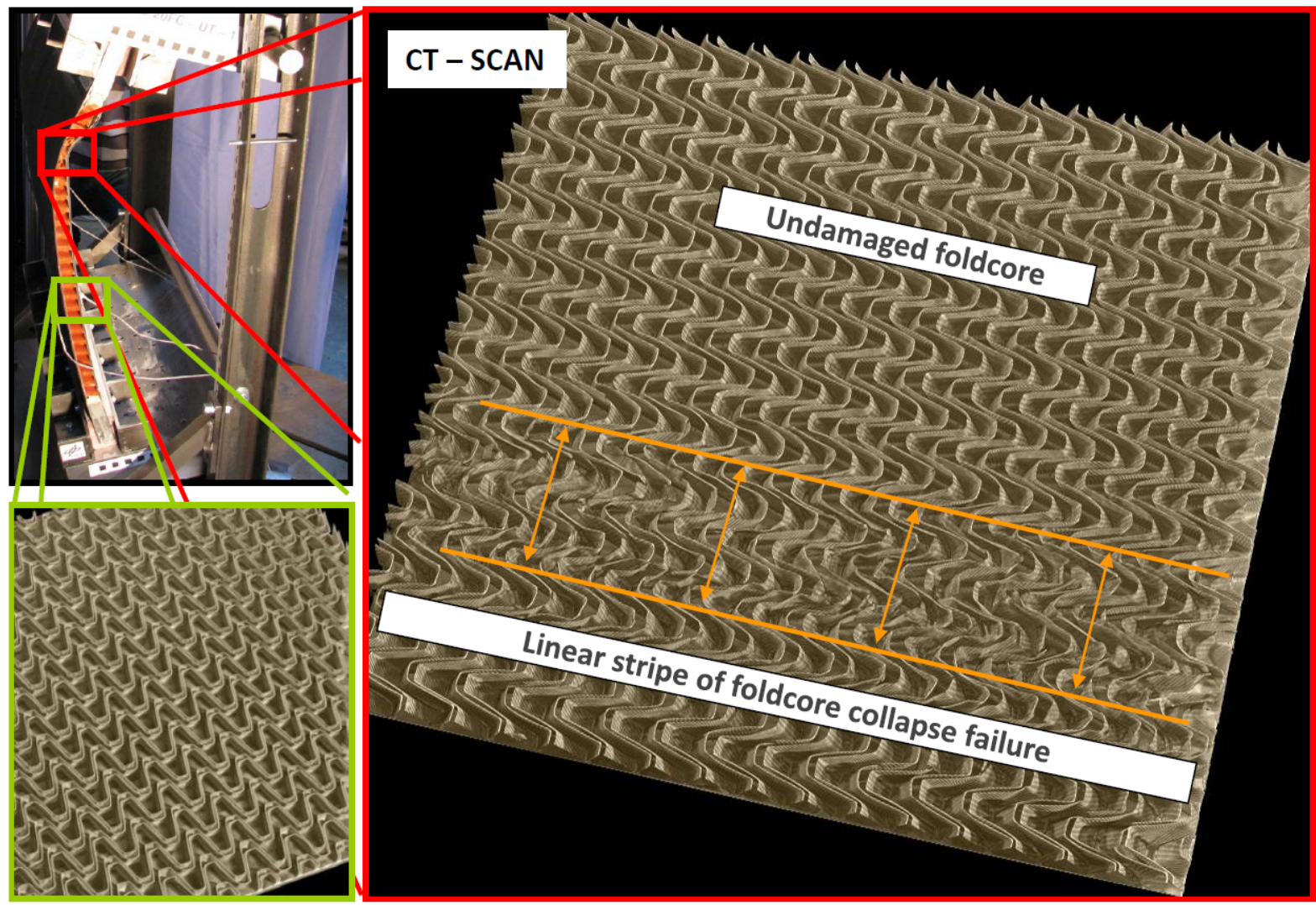

Fig. 5: 3D computed tomography of foldcore at failure position and at centerline

Beside the occurrence of local delamination zones both facesheets remained intact. From the crashworthiness point of view the obtained failure characteristics can be seen favourable since, on the one hand, the structural integrity is preserved after hinge development and, on the other hand, the passengers are shielded against possible fire hazard from both facesheets. The damage of the panel was scanned at the location of failure and at the center for more detailed analysis by 3D CT-Scans (computed tomography). Images of the CT-scans are provided in Figure 5. The images visualise the severity of core damage directly at the failure region. In the direct failure region, a linear strip of highly crushed foldcore is obtained. However, the extent of the damaged core region remains locally limited. The scans show the undamaged foldcore directly beside the damaged core. Therefore, the core failure does only progress along the flight direction, while the extent in the circumferential direction is limited. Therefore under crash this failure mode would initiate a kinematic hinge directly at failure position.

\section{Core Trigger concept}

For a crashworthy aircraft design structural components have to fail under specific loading conditions to obtain a crash kinematics which, one the one hand, limits the vertical acceleration loads of the passenger to avoid severe spine injuries and, on the other hand, enables sufficient energy absorption capability for various impact scenarios. This requires a robust failure initiation of fuselage panels under a predefined loading condition. 

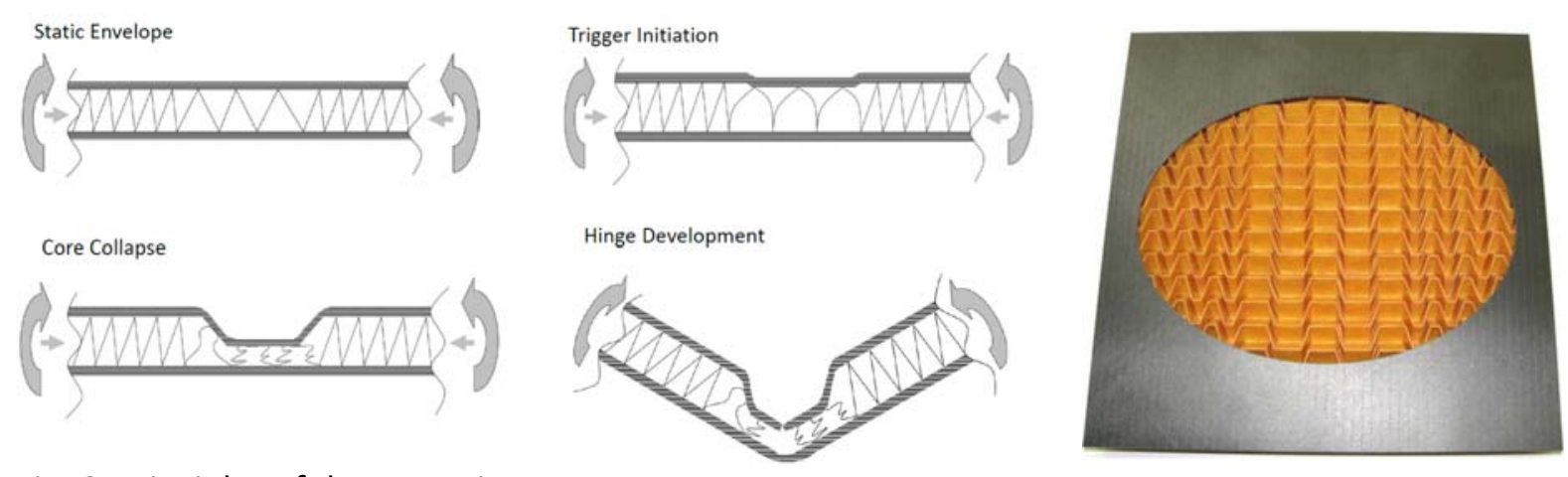

Fig. 6: Principles of the core trigger concept

For composite applications different trigger mechanisms under bending loads like ply drop off are known. However, all concepts have in common that the structural behaviour of the component is significantly influenced by the integrated trigger mechanism. The obtained failure mode of sandwich panels under crash-relevant loading indicates an additional trigger mechanism which could be applied to twin-walled fuselage panels. In the experimental test the panel failure was initiated by a collapsing core. Since the stiffness of a sandwich is mainly defined by the properties of the facesheets the structural response of sandwich construction is not influenced by local core modifications as long as the shear stiffness of the core fulfils the shear requirements. Therefore a new trigger concept is proposed for sandwich constructions by the local adaptation of the core failure characteristics [16]. The principles of the core trigger concept are provided in Figure 6. As long as the shear stiffness remains within the required static envelop, the core trigger does not affect the structural behaviour of fuselage panels. As soon as the loading condition of the panel exceeds a predefined loading the locally weakened core fails at the trigger position. Due to failure initiation, the core subsequently collapses. As the bending stiffness of the sandwich is reduced significantly at the position of failure, a kinematic hinge develops exactly at this location.

The flexibility of foldcores offers the unique possibility to implement the core trigger by a local modification of the fold pattern. The fold pattern used in the experiment consists of a zick-zack pattern with additional integrated horizontal edges. Since under compression loads thin walled folded structures fail due to buckling, the core compressive strength is affected if the stability properties of fold pattern are modified. Hence by modifying the length of the horizontal fold edge, the failure characteristics of the core can be adjusted according to hinge requirements. Since this modification can be directly implemented in the folding process, as shown in Figure 6 , no splicing of different core structures is required.

The possibility of tailoring a fold pattern according to defined static requirements using experimental material characterisation programs is economically not feasible. Therefore within the European funded project CELPACT numerical methodologies were investigated for modelling aramid paper structures [8]. Within this project a multi-layered modelling approach was developed and validated, which also takes into account the notable variation of the mechanical properties due to inhomogeneous fibre distribution in thickness direction [10]. 


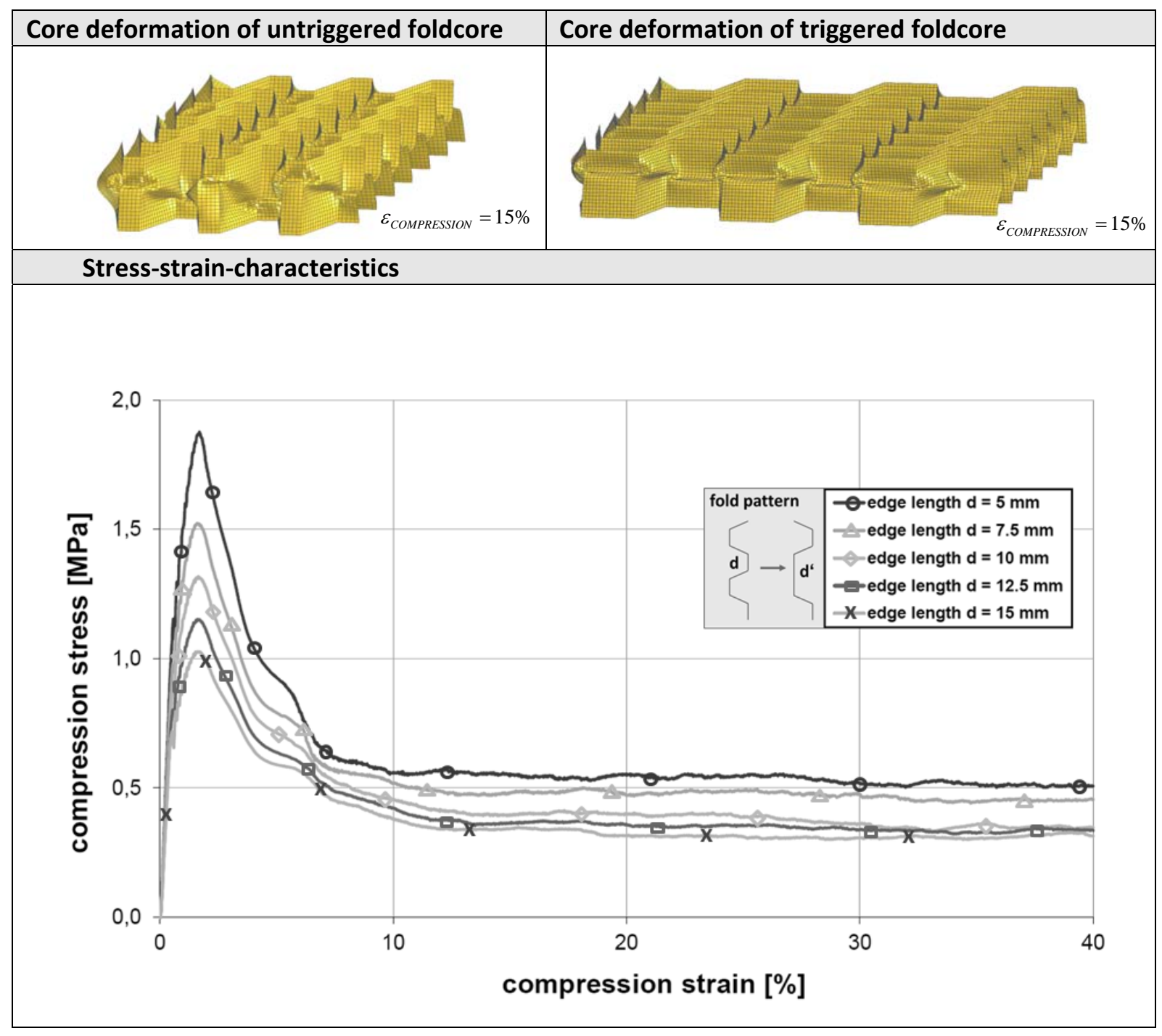

Fig. 7: Influence of horizontal fold edge modification on compression behaviour

The modelling approach developed in the CELPACT project for the explicit simulation environment was applied in this research study to identify the influence of the applied pattern modification on the structural properties of the core by sensitivity studies. Therefore, a numerical model consisting of $3 \times 5$ unit cells was built using a parametric modelling approach. In virtual core characterisation studies the length of the horizontal fold edge was increased from $5 \mathrm{~mm}$, which corresponds to the length of the reference pattern, in steps of $2.5 \mathrm{~mm}$ up to $15 \mathrm{~mm}$. In the characterisation studies the foldcores were compressed between two rigid surfaces and the structural response of the core was plotted. Figure 7 shows the obtained compressive stress-strain properties for the different horizontal fold edge lengths. The simulations indicate that the core modification especially affects the compressive failure strength of the core. With increasing edge length, the instability occurs at lower stress levels. Hence, with adaption of the edge length the failure characteristics of the core can be adjusted to the loading condition obtained in the sandwich structure when a failure is required to limit the passenger acceleration loads. For the investigated core pattern the failure strength of the core is reduced by $45.2 \%$ due to the length modification from $5 \mathrm{~mm}$ to $15 \mathrm{~mm}$. However, the plots also indicate that the crushing plateau and therefore the absorbed energy is also affected by the core modification in the same order of magnitude. The compressive stiffness is also affected by this modification. The effect on the compressive stiffness is a reduction of $27.7 \%$ due to the length modification from $5 \mathrm{~mm}$ to $15 \mathrm{~mm}$. 


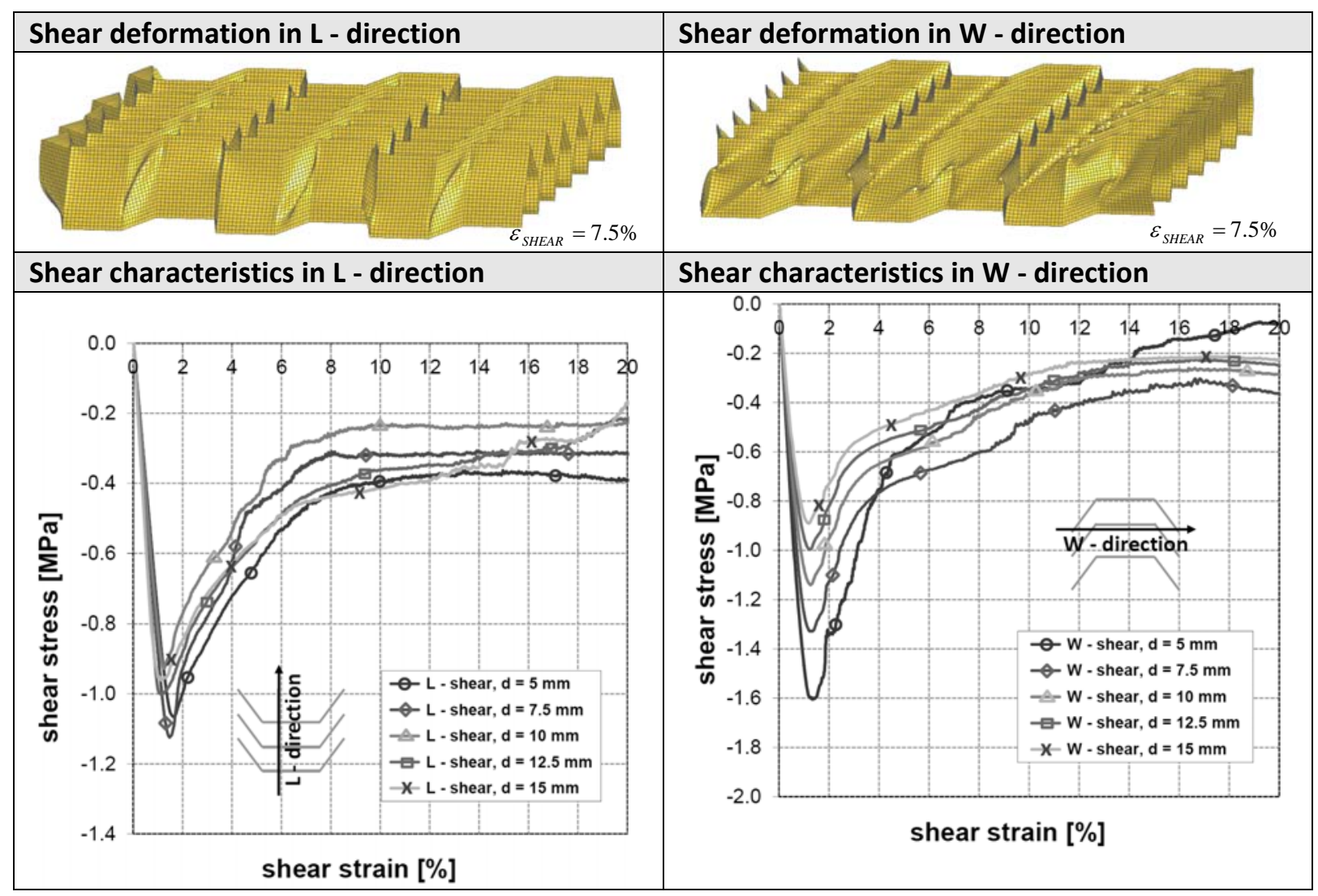

Fig. 8: Influence of horizontal fold edge modification on shear behaviour

Besides the compression properties the modification of the fold pattern also influences the shear behaviour. Therefore the effect of the modification on the shear properties was also investigated numerically. Since foldcores have direction dependent shear properties, the influence of the core modification was investigated in both the principal directions. Figure 8 depicts the shear response of the investigated fold pattern.

The simulations indicate that the modification especially affects the shear properties in W-direction. While shear failure strength reduces by $45.7 \%$ due to the length modification from $5 \mathrm{~mm}$ to $15 \mathrm{~mm}$, the reduction in L-direction is only $6 \%$. The shear stiffness in L-direction is also reduced $27 \%$ by this modification. However, the stiffness in the $\mathrm{W}$-direction even increases by $45 \%$ due to the longer fold edge.

The simulation studies indicate that the core properties can be influenced by the modification of the fold pattern. However, since a modification influences the complete structural response of the core in shear and in compression, the reduced core properties in trigger regions have to be investigated in detail. Since foldcores can be characterised virtually requiring low computational costs, virtual optimization procedures can be used to identify an optimised fold pattern that fulfils all static design requirements. The feasibility of virtual optimization studies could be shown by studies from Lülf [13] and Heimbs [18]. In the studies of Lülf the fold pattern was optimised by minimizing the penetration depth of rigid sphere impactor for defined impact scenarios using the optimization tool PAM-OPT. Heimbs, on the other hand, optimized the material description parameters for a given fold pattern to identify virtually the material input parameters that give the best correlation between material characterisation test and simulation using the optimization tool LS-OPT. 


\section{Verification of the core trigger concept}

For the verification of the core trigger concept a weakened core segment with an extent of $103 \mathrm{~mm}$ was integrated in the centre of the fuselage panel. For triggering, the horizontal fold edge was increased from $5 \mathrm{~mm}$ to $15 \mathrm{~mm}$. Besides the trigger integration, test conditions were kept identical to identify the effect of the core trigger.

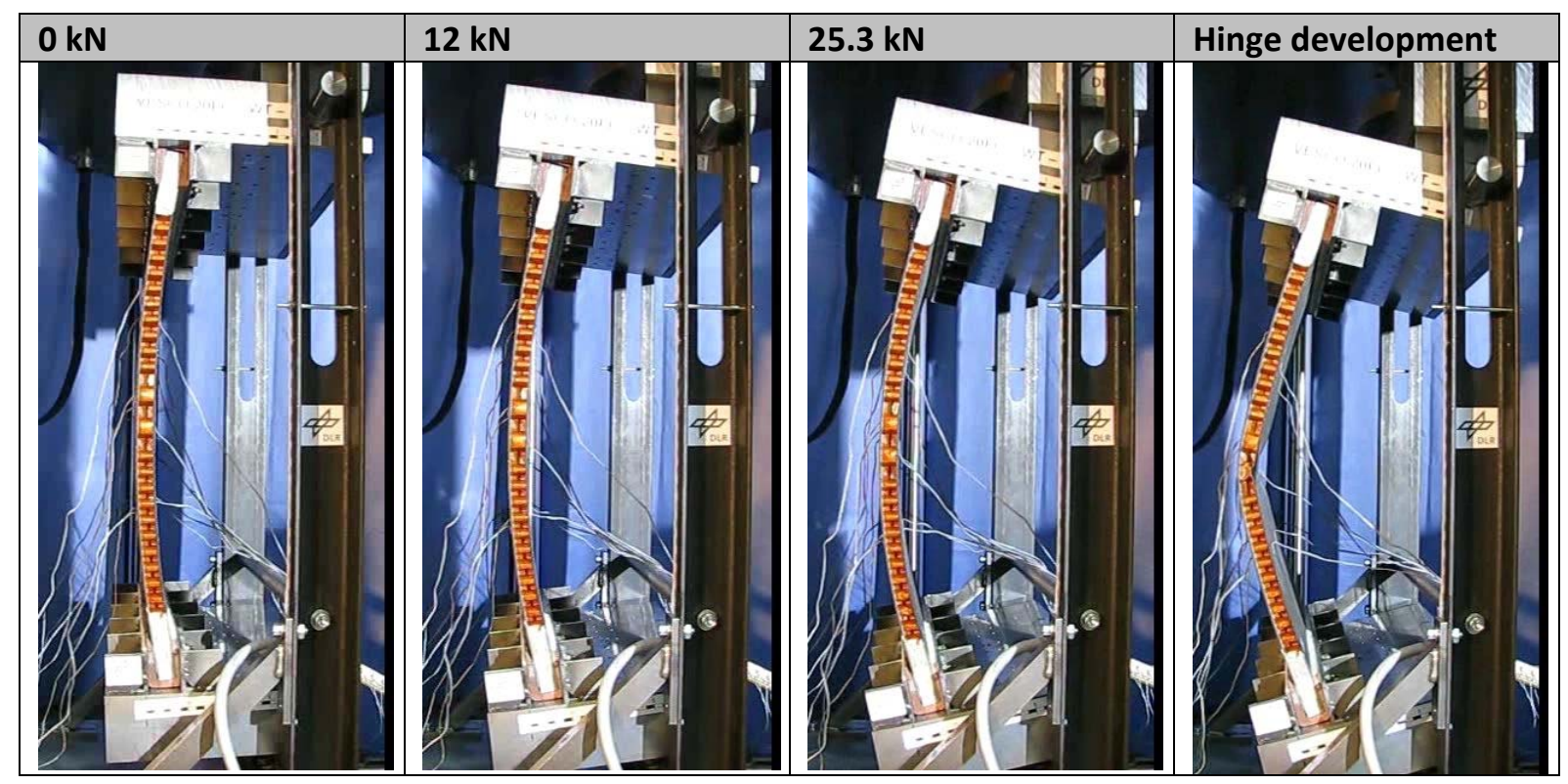

Fig. 9: Deformation and failure of a fuselage sandwich panel with foldcore trigger under a bendingcompression ratio of $200 \mathrm{~mm}$

Figure 9 shows the deformation and the failure of the triggered fuselage panel. The experiment proved that by integrating a core trigger, the failure of the panel can be influenced. In the experiment the failure was initiated by a stamp compression force of $25.3 \mathrm{kN}$ while the untriggered panel failed at a significant higher stamp force of $29.6 \mathrm{kN}$. Additionally, due to the trigger the failure occurred directly at the weakened core region whilst the untriggered panel failed due to local stress concentration directly at the load introduction as shown in Figure 4. For detailed failure analysis the damaged region was investigated using the 3D computed tomography. Images of the damaged region are shown in Figure 10. The images indicate that the failure of the panel was initiated due to a collapsing core. Since the degree of core damage decreases constantly from one side, the CT images also indicate a failure initiation from the panel edge, which propagated along the weakened core segment. In contrast to the test with the untriggered panel the inner facesheet of the panel ruptured as a result of the core collapse. The decrease in core damage could be explained by the assumption that after rupture initiation in the facesheet the failure propagated directly along the facesheet without severely damaging the core. 


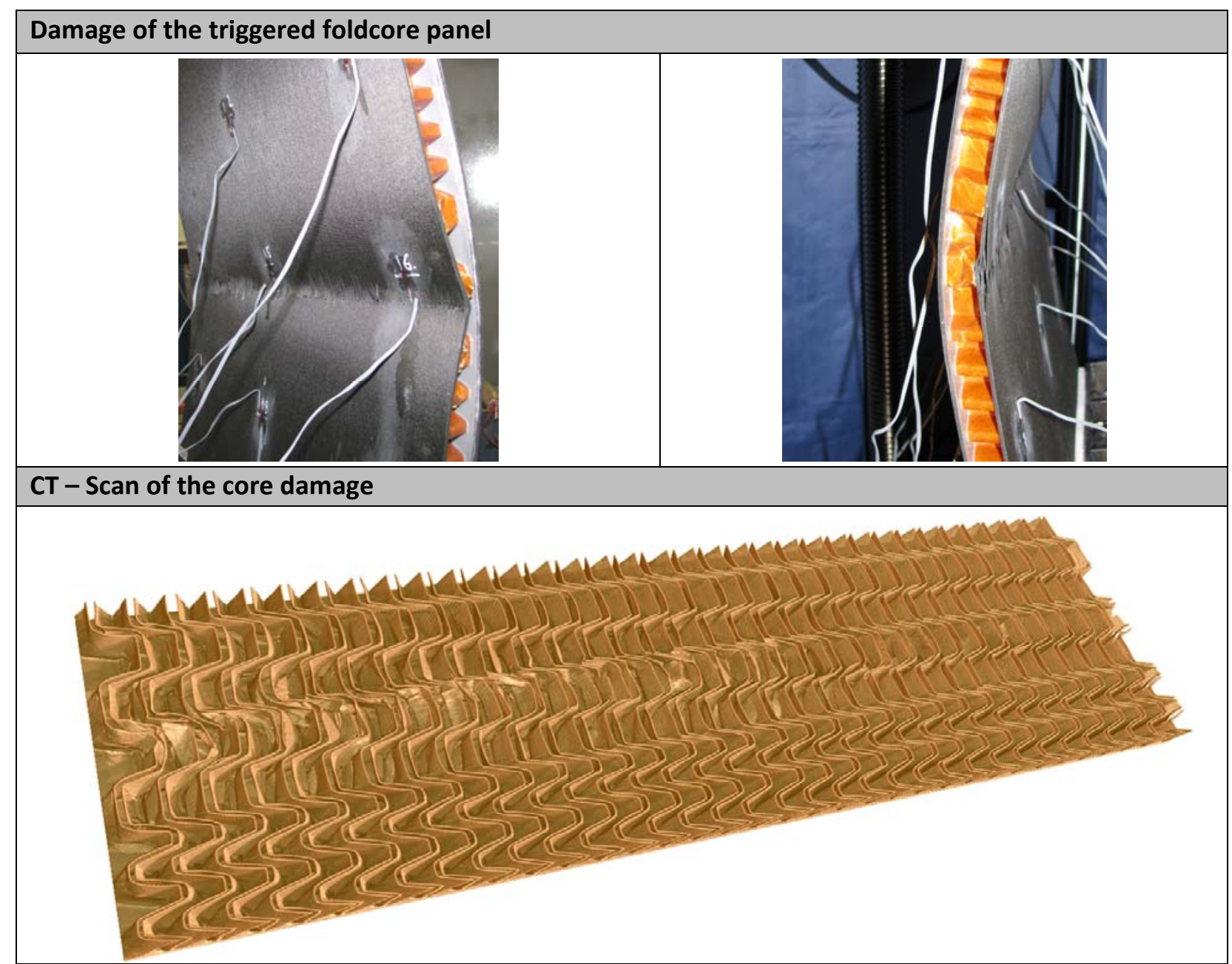

Fig. 10: Picture of the visual damage of the sandwich panel and 3D computed tomography of the core damage

Since the trigger concept was only verified by one component test an additional experiment was conducted with an identical triggered fuselage panel under a different bending to compression ratio. Instead of $200 \mathrm{~mm}$, the panel was positioned $180 \mathrm{~mm}$ away from the loading axis, which means that under this test condition the panel was investigated under a ratio of $A=180 \mathrm{~mm}$. The obtained deformation and panel failure is shown in Figure 11. Despite the different loading condition the panel exhibits the same failure characteristics as under a ratio $A=200 \mathrm{~mm}$. The panel is loaded elastically until the core collapses in the trigger region, which subsequently initiates a rupture of the inner facesheet. 


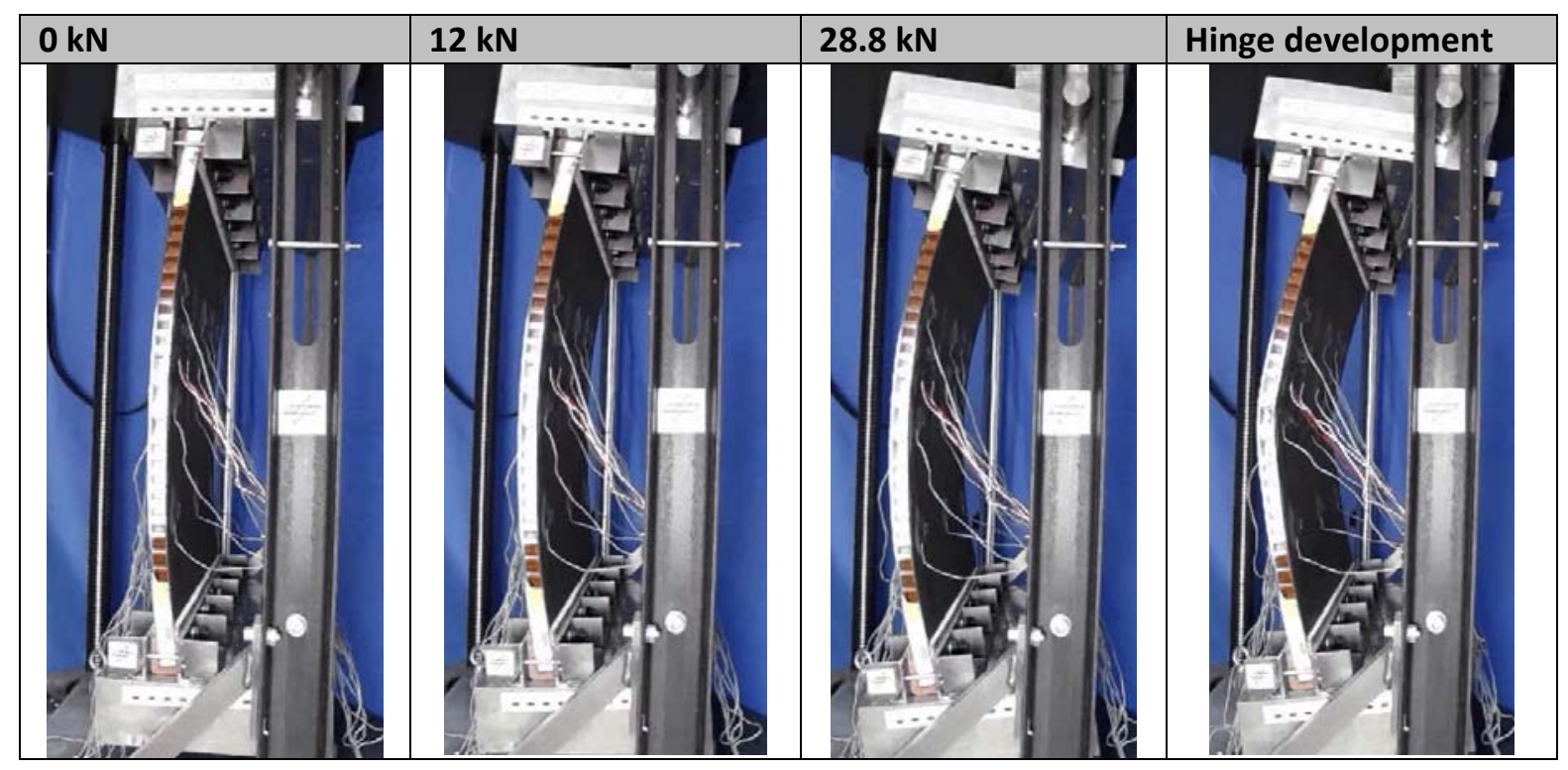

Fig. 11: Deformation and failure of a fuselage sandwich panel with foldcore trigger under a bendingcompression ratio of $180 \mathrm{~mm}$

The effect of the modified compression to bending ratio, on the other hand, can be recognised in the measured data. Instead of $25.3 \mathrm{kN}$ at $\mathrm{A}=200 \mathrm{~mm}$ the panel fails at a stamp loading which is $13.8 \%$ higher $[28.8 \mathrm{kN}]$. The increased failure loading can be explained by the dominance of the bending loads in regard to the compression loads. Since bending loads are the defining load component the $10 \%$ reduced leverage has to be compensated by higher stamp loads to obtain equivalent facesheet loading. Hence, for the initiation of a core trigger, bending is the defining parameter.

\section{Results and Discussions}

\subsection{Strain measurements}

In the tests, strain gauges were attached at the inner and outer facesheets at identical panel positions. Figure 12 depicts the measured facesheet strains at the strain gauge positions 4 and 6 versus the measured compressive stamp force for the untriggered panel at $A=200 \mathrm{~mm}$. The strain measurements show that the facesheets are loaded up to $0.9 \%$ strain during the experiment. This result supports the finding that an unstiffened twin-walled fuselage panel is able to store significant elastic energy in the facesheet before failing. The strain measurement on the outer facesheet strains is approximately $0.72 \%$ while compression strains of between $0.84 \%$ and $0.9 \%$ are observed. Since inner and outer facesheet have the identical laminate setup the significant difference in strain directly indicates the effect of the additional compressive load component in the experiment. 


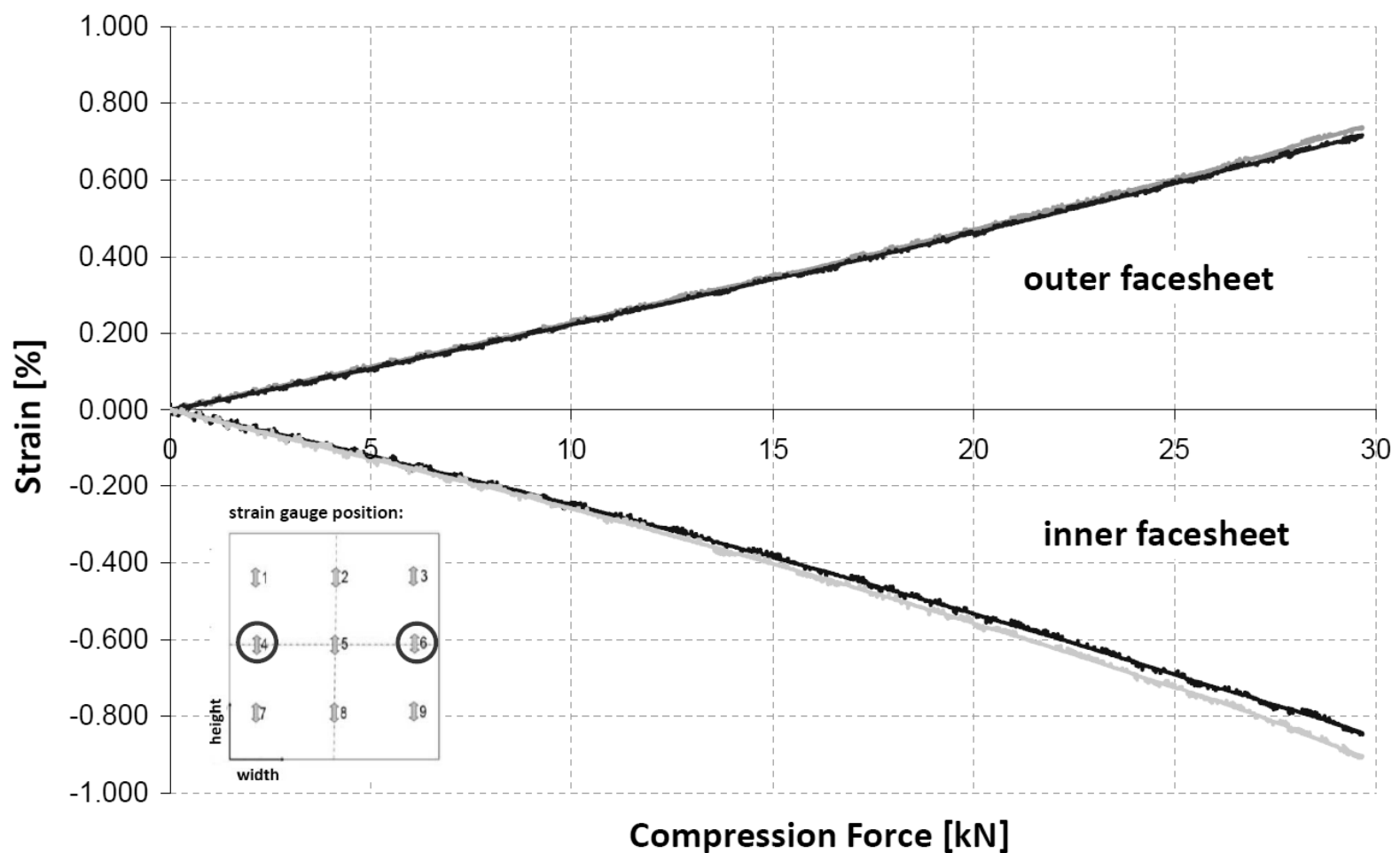

Fig. 12: Facesheet strains vs. stamp force of the untriggered panel under a bending-compression ratio of $200 \mathrm{~mm}$ at two strain gauge positions

\subsection{Structural effect of a core trigger}

In Figure 13 the measured strains on inner and outer facesheets are compared for the triggered and the untriggered panel at $A=200 \mathrm{~mm}$ to identify the effect of the core trigger on the structural behaviour of the panel. The measured strain data indicates that both panels show an almost identical deformation characteristic within the elastic domain. This supports the assumption that due to the unaffected facesheets a core trigger has only small influence on the elastic structural behaviour. The small impact on the elastic behaviour by significantly affecting the failure initiation is the main advantage of a core trigger compared to conventional trigger mechanisms.

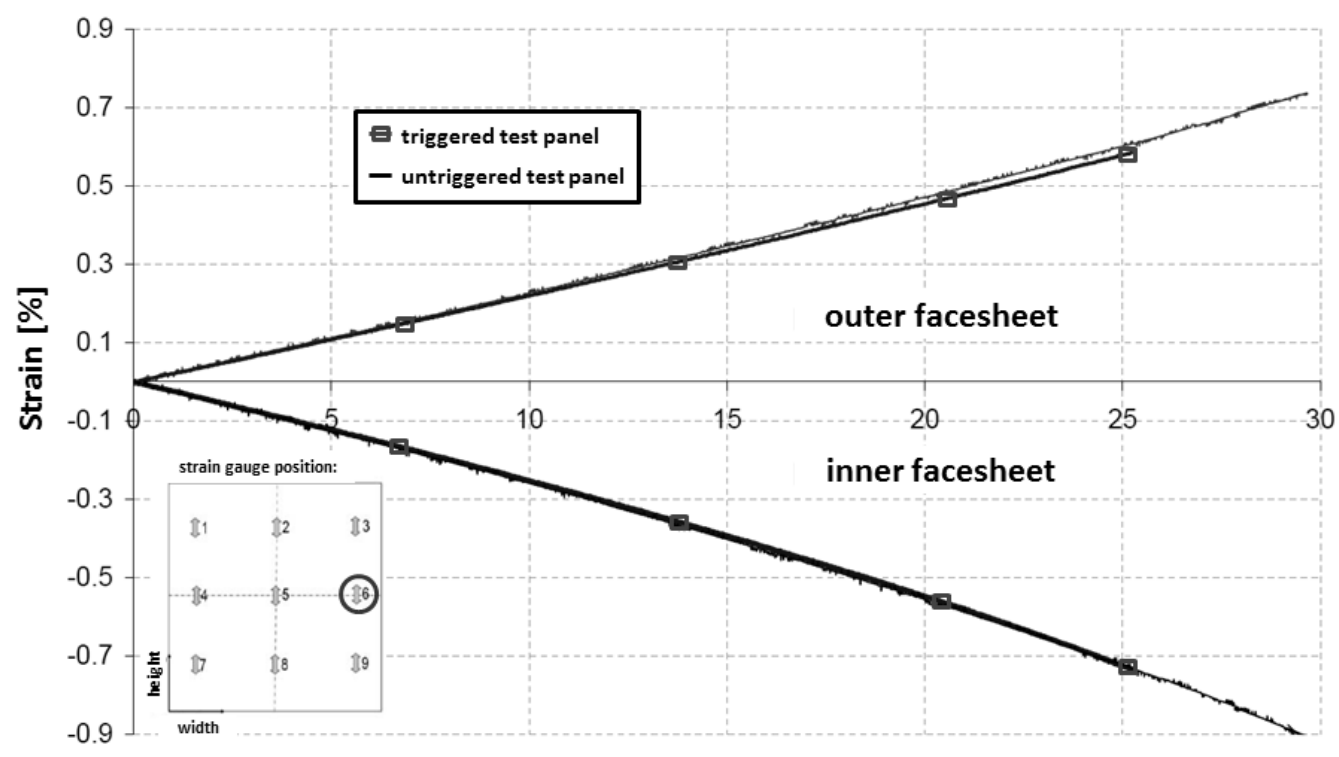

Compression Force $[\mathrm{kN}]$

Fig. 13: Influence of the core trigger on the facesheet strain under a bending-compression ratio of 200 $\mathrm{mm}$ at strain gauge position 6 


\subsection{Photogrammetric strain field measurements}

In the trigger region the panel is loaded with pure bending. Therefore in this region the core is loaded only by negligible shear forces. Since failure initiation by shear can be excluded core compression loads have to be the dominating factor for the successful triggering in the experiments. For visual detection of the compression forces 3D photogrammetric strain field measurements were conducted using a 3D optical measurement system from GOM. In Figure 14 the strain field within and outside of the trigger region is shown for $25 \%$ and $50 \%$ of the failure load under a ratio of $A=200 \mathrm{~mm}$. The results show that at $25 \%$ failure load only a very local region is under compression. However, the extent of the compression strain increases noticeably due to the increase from $25 \%$ to $50 \%$ failure load in the trigger region. The same behaviour is not observable outside the trigger region. There the differences in the compression strain for the same load steps are negligibly small. The identified compressive strain concentrations directly at the inner facesheet/core interface correspond to the exact location of failure initiation in the test. Therefore the photogrammetric strain field measurement supports the assumption of a failing core due to compression loads. The cause of the core compression forces is based on the strained curved facesheets. Whilst the facesheets are mainly loaded in bending, the resulting curvature is a combination of the curvature of the fuselage and the deflection due to the bending.

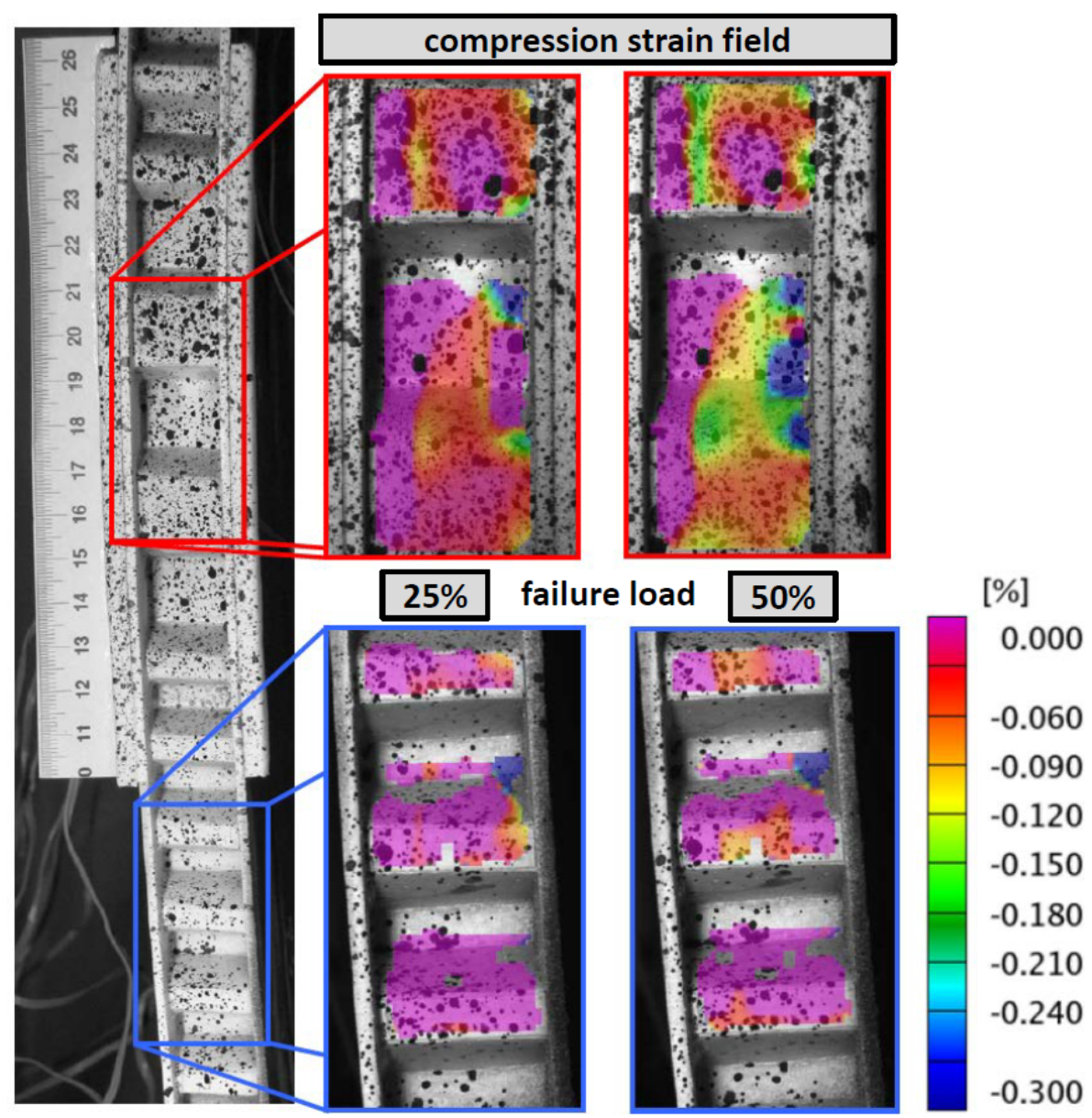

Fig. 14: Photogrammetric measurement of compression strain field of triggered and undisturbed foldcore region $(A=200 \mathrm{~mm})$ 


\subsection{Energy absorption capability}

The reduced strain during failure also indicates that the energy absorption capability of the panel is reduced by the core trigger. In the conducted experiment, if approximating the energy absorption capability of the tested panel by integrating the stamp loading up to failure, a decrease from $3 \mathrm{~kJ} / \mathrm{m}$ to $1.9 \mathrm{~kJ} / \mathrm{m}$ respective to the width of the panel is obtained. This means that the used triggering reduced the energy absorption capability of the fuselage panel. However, as shown in Figure 7, by adjusting the horizontal edge length, the energy absorption capability can be increased to fulfil the hinge requirements. However, it has to be considered, that with increasing similarity of the fold patterns in the trigger region and the neighbouring undisturbed regions the robustness of the core trigger mechanism declines. Additionally, the energy is absorbed mainly by the elastic deformation of the facesheets during failure initiation. In the post failure domain only low energy absorption was obtained in the experiments.

\subsection{Application of compression - bending tests}

The large structures which are necessary to introduce combined bending and compression load limited the number of tests. Therefore only three destructive tests could be conducted. Therefore additional tests would be needed to exclude a possible influence of imperfections on the test results. Hence, as long as only the material characteristic has to be investigated, common material tests as compression tests [18], 3-point bending [22] [23] or 4-point bending tests [18] [22] are preferable due to the small specimen size required. However, as soon as the failure of a structure has to be investigated under defined combined loading conditions, a more complex test procedure is needed. The functionality of trigger mechanisms, as the presented core trigger, can only be proven experimentally introducing the same loading conditions as during the investigated crash event. Simplifying the test using 3-point- of 4point-bending test poses the risk of higher failure loads or in the worst case even the development of a different failure mode of the specimen.

\section{Conclusions}

In the presented study the failure mechanisms of twin-walled fuselage panels with foldcore were investigated experimentally under crash relevant compression-bending loads. For combined loading an experimental test setup was developed, which enables the investigation of panel failures under defined mixed loading conditions. The experiment showed a panel failure due to local stress concentration at the load introduction. Using 3D computed tomography severe core crushing was detected at the position of failure whilst the facesheets remained undamaged beside local delamination zones. Since the damage was controlled by core failure a core trigger concept was developed which uses a locally weakened core region to control the failure initiation of the panel. Performing numerical simulations on foldcore unit cells the effect of modified fold patterns on the structural behaviour was analysed to identify an efficient core trigger. Simulations showed that with local modifications in the fold pattern the core properties can be adjusted to fail under predefined loading conditions. To identify the effect of a core trigger a fuselage panel with integrated foldcore trigger was investigated under identical test condition. In the experiment the core trigger concept could be verified by moving the failure position directly into the triggered core region. The robustness of the core trigger could be shown in an additional test at modified loading condition.

The functionality of the core trigger could only be shown for unstiffened fuselage panels. Since stiffening structural members like frames will significantly influence the stress distribution of the core. Additional studies are necessary to investigate and understand the effect of stiffening structural components on the functionality of a core trigger. 


\section{Acknowledgements}

The research leading to these results has partially received funding from the Helmholtz Association of German Research Centres. Parts of this work have been performed in cooperation with the Institute of Aircraft Design of the University of Stuttgart. The first author acknowledges good support through the university of Stuttgart provided by technical discussions, information about structural designs and finally by the manufacturing of the specimens.

\section{References}

[1] Federal Register /Vol. 72, No. 186, Special Conditions: Boeing Model 787-8 Airplane; Crashworthiness, http://gpo.gov/fdsys/pkg/FR-2007-09-26/pdf/E7-18942.pdf, September, 2007

[2] Ch. Kindervater, Validation of Crashworthiness Simulation and Design Methods by Testing of a Scaled Composite Helicopter Frame Section, AHS Conference, May 2011

[3] Jackson, A., Dutton, S. Gunnion, A.J., Kelly, D.W., Effect of Manufacture and Laminate Design on Energy Absorption of Open Carbon-Fibre/Epoxy Sections, 17th Int. Conference on Composite Materials (ICCM-17), Edinburgh, UK, 2009.

[4] José G. Pérez, Energy Absorption and Progressive Failure Response of Composite Fuselage Frames, Master thesis, Virginia Polytechnic Institute, Juli, 1999

[5] R. Hashemi, Sub-component dynamic tests on an A320 rear fuselage, Cranfield Impact Centre Limted, Sub-task 2.4 of the European Community funded research project 'Crashworthiness for commercial aircraft', 1994

[6] M. Waimer, The Kinematics Model - A Numerical Method for the Development of a Crashworthy Composite Fuselage Design of Transport Aircraft, Sixth Triennial International Aircraft Fire and Cabin Safety Research Conference, October 2010

[7] EMIR, "Engineering mehrfunktionaler Integralstrukturen CfK-Rumpf", LuFo III (German national aeronautics research project), BMBF, (2003-2007).

[8] CELPACT, Cellular structures for impact performance, EU Research Project, FP6-031038, (20062009)

[9] K. Drechsler, Manufacturing of folded core-structures for technical applications, 25th International SAMPE Europe Conference, Paris, 508-513, 2004

[10] S. Kilchert, Finite element modelling of phenolic resin impregnated aramid paper adopted in foldcore sandwich structures, German Aerospace Center, CST 2008, Civil-Comp Press, paper 316, 2008

[12] D. Hachenberg, C. Mudra, M. Nguyen, Folded structures - an alternative core material for future sandwich concepts, DGLR Conference, Munich, November 2003

[13] F. A. Lülf, Optimisation of folded core geometry by FE models for different load cases, Master's thesis, University of Stuttgart, Institute of Statics and Dynamics of Aerospace Structures, 2008

[14] P. Middendorf, S. Heimbs, Technologische Integration ganzheitlicher Rumpffunktionen in Strukturelemente "TIGRIS", final research report project CORUBA, EADS IW, September 2007 
[15] Boeing Company, Energy Absorbing Structure for Aircraft, UK Patent Application, GB 2444645 A, June 2008

[16] R. Sturm, Y. Klett, Kerntriggerung durch gezielte lokale Faltkernmodifikation, patent 102009047 040, Germany, June 2012

[17] S. Kilchert, Nonlinear finite element modelling of degradation and failure in folded core composite sandwich structures, PhD thesis, University of Stuttgart, ISRN DLR-FB--2013-22, August 2013

[18] S. Heimbs, Sandwichstrukturen mit Wabenkern: Experimentelle und numerische Analyse des Schädigungsverhaltens unter statischer und kurzzeitdynamischer Belastung, PhD thesis, Kaiserslautern University of Technology, 2008

[19] M. Waimer, Development of a Kinematics Model for Assessment of Global Crash Scenarios of a Composite Transport Aircraft Fuselage, PhD thesis, University of Stuttgart, ISRN DLR-FB-2013-28, September 2013

[20] L. Kärger, Stiffness and Failure behaviour of folded sandwich cores under combined transverse shear and compression, Composite Part A 38 (2007) 1288-1295, 2007

[21] R.S. Thomson, Simulation of impact on sandwich structures, Composite Structures 67 (2005) 217227, 2005

[22] E. Gdoutos, Failure of sandwich structures, $11^{\text {th }}$ National Congress on Theoretical and Applied Mechanics, Bulgaria, 2009

[23] N.A. Fleck, Collapse of truss core sandwich beams in 3-point bending, International Journal of Solids and Structures 38 (2001) 6275-6305, 2001

[24] R. Sturm, Impactsimulation auf Rumpfschalen mit gefalteter Kernstruktur, Deutsches Zentrum für Luft- und Raumfahrt, Interner Bericht, DLR-IB 435-2005/22

[25] L. Aktay, A. F. Johnson, Numerical modelling of honeycomb core crush behaviour, Engineering Fracture Mechanics 75, 2007

[26] D. Zankert, Sandwich construction, ISBN 0947817778, 1995

[27] S. Fischer, Numerische Simulation der mechanischen Eigenschaften von FaltkernSandwichstrukturen, PhD thesis, University of Stuttgart, ISBN 978344012583, 2012

[28] A. Johnson, Modelling Impact Damage in Double-Walled Composite Structures, VIII International Conference on Computational Plasticity, Barcelona, 2005

[29] Y. Klett, Auslegung multifunktionaler isometrischer Faltstrukturen für den technischen Einsatz, PhD thesis, University of Stuttgart, ISBN 978-3843910255, 2013

Keywords: crash; sandwich structures, foldcore, energy absorption 